\title{
Catalytic and asymmetric aziridination of alkenes catalysed by a chiral manganese porphyrin complex
}

\author{
Tat-Shing Lai, ${ }^{a}$ Hoi-Lun Kwong, ${ }^{b}$ Chi-Ming Che ${ }^{* a}$ and Shie-Ming Peng ${ }^{c}$ \\ ${ }^{a}$ Department of Chemistry, The University of Hong Kong, Pokfulam Road, Hong Kong, PR China \\ ${ }^{b}$ Department of Biology and Chemistry, City University of Hong Kong, Tat Chee Avenue, Kowloon Tong, Hong Kong, PR China \\ ${ }^{c}$ Department of Chemistry, National Taiwan University, Taipei, Taiwan
}

A $D_{4}$-manganese(III) porphyrin is utilized to catalyze aziridination of styrene-type substrates with enantiomeric excess ranging from 43 to $68 \%$; evidence for a $\mathrm{Mn}^{\mathrm{IV}}$ reactive intermediate in the catalysis was obtained from spectroscopic studies and organic product analysis.

Metalloporphyrins have potential applications in asymmetric organic syntheses. ${ }^{1}$ When compared to metal Schiff-base complexes, they can offer more robust catalysts ${ }^{2}$ that can lead to high product turnover numbers and facilitate the detection and/ or isolation of highly reactive intermediates in the catalyses. 3,4 Here, we report the evidence of a $\mathrm{Mn}^{\mathrm{IV}}$ reactive intermediate in a chiral manganese $D_{4}$-porphyrin-catalyzed nitrene transfer reaction. This reaction also features the first example of chiral porphyrin catalysts for asymmetric alkene aziridination with moderate enantioselectivities.

The chiral manganese(III)porphyrin catalyst $\mathrm{Mn}\left(\mathrm{P}^{*}\right)(\mathrm{MeO}-$ $\mathrm{H})(\mathrm{OH}) \quad\left[\mathrm{H}_{2} \mathrm{P}^{*}=5,10,15,20\right.$-tetrakis $(1,2,3,4,5,6,7,8$-octahydro-1,4 : 5,8-dimethanoanthracen-9-yl)porphyrin] 1 used in this work was prepared by the method of Halterman and Jan. ${ }^{5}$ Upon recrystallization of $\mathbf{1}$ from $\mathrm{MeCN}-\mathrm{MeOH}-\mathrm{CH}_{2} \mathrm{Cl}_{2}(1: 10: 2$

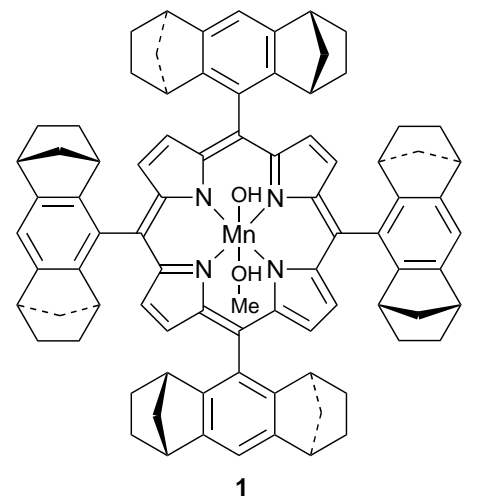

$\mathrm{v} / \mathrm{v})$ red crystals of $\left[\mathrm{Mn}\left(\mathrm{P}^{*}\right)(\mathrm{MeOH})(\mathrm{OH})\right] \cdot \mathrm{MeCN}$. $\mathrm{MeOH} \cdot 3 \mathrm{H}_{2} \mathrm{O}$ were obtained. Its structure was determined by $\mathrm{X}$-ray crystal analysis $\dagger$ and a perspective view of the molecule is shown in Fig. 1.

With this bulky porphyrin ligand, a new manganese species which is capable of catalyzing nitrene transfer to alkenes is detected immediately after mixing stoichiometric amount of $\mathbf{1}$ and $\mathrm{PhINTs}$ in $\mathrm{CH}_{2} \mathrm{Cl}_{2}$ at room temp. This species has an apparent room temp. half-life of $c a .30 \mathrm{~min}$ in $\mathrm{CH}_{2} \mathrm{Cl}_{2}$ and is proposed to be a Mn ${ }^{I V}-\mathrm{PhINTs}$ adduct (Scheme 1). The Mn ${ }^{\mathrm{IV}}$ formulation is based on the following reasons: its UV-VIS absorption spectrum (Fig. 2) with a Soret band at $433 \mathrm{~nm}$, is similar to $\mathrm{Mn}^{\mathrm{IV}}$ porphyrin complexes reported previously; ${ }^{6}$ its EPR spectrum shown in Fig. 3 is consistent with a high-spin octahedral $\mathrm{d}^{3}$ ion. ${ }^{6}$ It reacts rapidly with alkenes such as styrene to regenerate the starting complex $\mathbf{1}$ with the concomitant formation of aziridine in good yield and in moderate enantiose- lectivity ( $>70 \%$ yield and $50 \%$ ee for styrene) (Scheme 1 ). The UV-VIS spectral changes of its reaction with styrene are shown in Fig. 2. With excess styrene, the reaction follows pseudo-firstorder kinetics (monitored at $480 \mathrm{~nm}$ ) and the observed rate law is: rate $=k_{2}\left[\mathrm{Mn}^{\mathrm{IV}}\right][$ styrene $]$ with the second order rate constant being $2.0 \times 10^{-3} \mathrm{dm}^{3} \mathrm{~mol}^{-1} \mathrm{~s}^{-1}$. Attempts were made to isolate this $\mathrm{Mn}^{\mathrm{IV}}-\mathrm{PhINTs}$ species in solid form by removal of the solvent at low temperature. A brown solid was obtained and its IR spectrum showed bands at 1340 and $1159 \mathrm{~cm}^{-1}$ assigned to the tosyl moiety. However, this species slowly converted to



Fig. 1 Perspective view of $\left[\mathrm{Mn}\left(\mathrm{P}^{*}\right)(\mathrm{MeOH})(\mathrm{OH})\right]$. Selected bond lengths $(\AA)$ and angles $\left(^{\circ}\right)$ : Mn-N(1) 2.004(7), Mn-N(2) 1.992(6), Mn-N(3) 2.019(7), $\mathrm{Mn}-\mathrm{N}(4)$ 1.995(7), $\mathrm{Mn}-\mathrm{O}(1)$ 2.268(7), $\mathrm{Mn}-\mathrm{O}(2)$ 2.251(7); $\mathrm{O}(1)-\mathrm{Mn}-\mathrm{O}(2)$ 178.9(3), O(1)-Mn-N(1), 90.4(3), O(1)-Mn-N(2) 89.5(3), $\mathrm{O}(2)-\mathrm{Mn}-\mathrm{N}(1)$ 88.8(3), O(2)-Mn-N(2) 89.7(3), N(1)-Mn-N(2) 89.8(3), $\mathrm{N}(1)-\mathrm{Mn}-\mathrm{N}(4)$ 90.1(3)

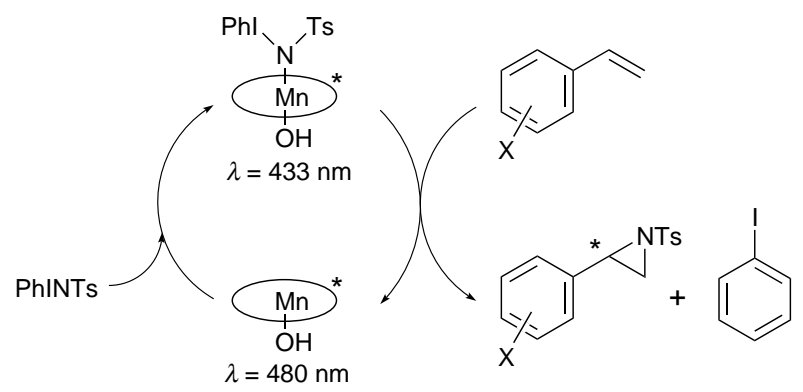

Scheme 1 Proposed catalytic cycle for enantioselective aziridination involving a $\mathrm{Mn}^{\mathrm{IV}}-\mathrm{PhINTs}$ adduct 


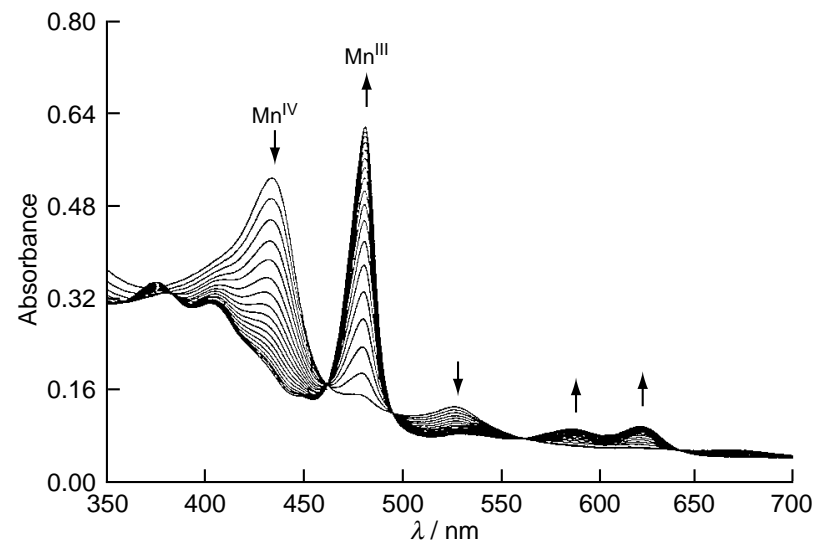

Fig. 2 UV-VIS monitoring of the reaction between the $\mathrm{Mn}^{\mathrm{IV}}-\mathrm{PhINTs}$ adduct and styrene $\left(0.48 \mathrm{~mol} \mathrm{dm}^{-3}\right)$; scan interval, $1 \mathrm{~min}$

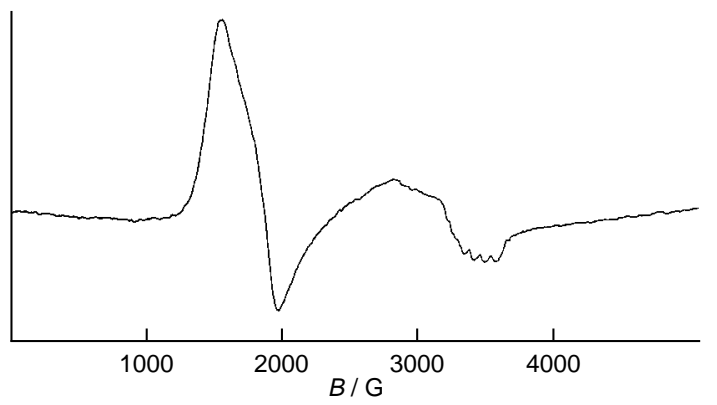

Fig. 3 EPR spectrum of the reactive intermediate generated by mixing 1 and PhINTs in $\mathrm{CH}_{2} \mathrm{Cl}_{2}$ at room temp. and then cooled to $119 \mathrm{~K}$

$\mathbf{1}$ and some unidentifiable substance in solution at room temperature.

The aziridination and amination of alkenes can be rendered catalytic and enantioselective by addition of PhINTs. The results are listed in Table 1. Enantioselectivity was moderate, ranging from 40 to $68 \%$ depending on both the position and the electronic demand of the substituents, with the best result obtained with $o$-bromostyrene. At a catalyst:PhINTs : alkene ratio of $1: 200: 4000$, the chemical yields based on the amount of PhINTs used were moderate and note that the turnover numbers were good, usually around 100 . With another portion of PhINTs added, the turnover number increased from 130 to ca. 292 in the case of styrene (Entries 2 and 3). At a catalyst:PhINTs:alkene ratio of $1: 600: 4000$, a turnover number of 480 and aziridine at comparable ee were obtained (Entry 4). These turnover numbers are relatively high when compared with that of the reported chiral Mn-salen catalysts. ${ }^{7}$ For alkenes that did not possess allylic hydrogen atom (Entries 1-11), aziridine was the only product. However, for alkenes that have allylic hydrogen (Entries 12 and 13), allylic amination became the major product with only minimal aziridination occurred. This result is intriguing since only a few methods for allylic amination are known. ${ }^{8}$ From the yields and turnover numbers, the present findings feature one of the best results for catalytic allylic amination of alkenes. The absolute configuration of the aziridine obtained was $R$.

We acknowledge support from the Hong Kong Research Grants Council and The University of Hong Kong.

\section{Footnotes and References}

* E-mail: cmche@hkucc.hku.hk

$\dagger$ Crystallographic data: $\mathrm{C}_{88} \mathrm{H}_{94} \mathrm{MnN}_{5} \mathrm{O}_{6}, M=1372.73$, crystal size 0.30 $\times 0.50 \times 0.60 \mathrm{~mm}$, orthorhombic, space group $P 2_{1} 2_{1} 2_{1}, a=14.029$ (2), $b=20.283(3), c=27.596(3) \AA, U=7852.2(17) \AA^{3}, Z=4, D_{c}=1.161$ $\mathrm{g} \mathrm{cm}^{-3}, \mu(\mathrm{Cu}-\mathrm{K} \alpha)=17.83 \mathrm{~cm}^{-1}, F(000)=2920,2 \theta_{\max }=140.0^{\circ}, \lambda(\mathrm{Cu}-$ $\mathrm{K} \alpha)=1.5418 \AA$, scan type $\theta-2 \theta, T=298 \mathrm{~K}$, no. of unique reflections $=8118$, no. of observed reflections $[I>2.0 \sigma(I)]=4713$, unit
Table 1 Catalytic asymmetric aziridination and amination of alkenes using PhINTs with complex 1 as the catalyst ${ }^{a}$

\begin{tabular}{|c|c|c|c|c|c|}
\hline Entry & Substrate & Product & Yield $^{b}(\%)$ & $\%$ ee & Turnover \\
\hline 1 & & & 71 & 49 & 130 \\
\hline 2 & & & $73^{d}$ & 55 & 142 \\
\hline 3 & & & $72^{e}$ & 51 & 292 \\
\hline 4 & & & $60^{f}$ & 43 & 480 \\
\hline 5 & & & 66 & 44 & 132 \\
\hline 6 & & & 43 & 45 & 86 \\
\hline 7 & & & $47^{d}$ & 51 & 94 \\
\hline 8 & & & 49 & 49 & 98 \\
\hline 9 & & & $53^{d}$ & 52 & 106 \\
\hline 10 & & & 44 & 62 & 88 \\
\hline 11 & & & $56^{d}$ & 68 & 112 \\
\hline 12 & & & 73 & n.d. ${ }^{g}$ & 146 \\
\hline 13 & & & 76 & - & 152 \\
\hline
\end{tabular}

a Reaction conditions: $0.50 \mathrm{~mol} \%$ catalyst, 20-fold excess of substrate, 200 mg PhINTs and $2 \mathrm{ml} \mathrm{CH}_{2} \mathrm{Cl}_{2} .{ }^{b}$ Isolated yield were based on the amount of PhINTs used. ${ }^{c}$ Ee values are determined by HPLC analysis (Whelk-O1). ${ }^{d}$ With 4-phenylpyridine $N$-oxide $(5 \mathrm{mg})$ as additive. ${ }^{e}$ Addition of another portion of $200 \mathrm{mg}$ of PhINTs to the reaction after the first portion of PhINTs was consumed. $f$ Catalyst:PhINTs $:$ alkene $=1: 600: 4000 .{ }^{g}$ Not determined.

weights were used. No. of refined parameters $=902$, refinement program NRCVAX, $R_{\mathrm{f}}=0.063, R_{\mathrm{w}}=0.072, \mathrm{GOF}=1.87$. The final Fourier difference map showed residual extrema in the range of 0.56 to $-0.43 \mathrm{e}$ $\AA^{-3}$. CCDC $182 / 651$.

1 (a) Y. Naruta, F. Tani, N. Ishihara and K. Maruyama, J. Am. Chem. Soc., 1991, 113, 6865; (b) J. P. Collman, L. J. Lee, C. J. Kellen-Yuen, X. Zhang, J. A. Ibers and J. I. Brauman, J. Am. Chem. Soc., 1995, 117, 692; (c) W. C. Lo, C. M. Che, K. F. Cheng and T. C. W. Mak, Chem. Commun., 1997, 1205.

2 D. Dolphin, T. Traylor and L. Y. Xie, Acc. Chem. Res., 1997, 30, 251.

3 J. T. Groves and T. Takahashi, J. Am. Chem. Soc., 1983, 105, 2073 J. T. Groves and Y. Watanabe, J. Am. Chem. Soc., 1988, 110, 8443; W. H. Leung and C. M. Che, J. Am. Chem. Soc., 1989, 111, 8812; J. P. Collman, E. Rose and G. D. Venburg, J. Chem. Soc., Chem. Commun., 1993, 935; S. M. Au, W. H. Fung, M.-C. Cheng, C. M. Che and S. M. Peng, Chem. Commun., 1997, 1655.

4 R. Breslow and S. H. Gellman, J. Chem. Soc., Chem. Commun., 1982, 1400; E. Svastit, J. H. Dawson, R. Breslow and S. H. Gellman, J. Am. Chem. Soc., 1985, 107, 6427; D. Mansuy, J.-P. Maby, A. Dureault, G. Bedi and P. Battioni, J. Chem. Soc., Chem. Commun., 1984, 1161; J.-P. Mahy, G. Bedi, P. Battioni and D. Mansuy, Tetrahedron Lett., 1988, 29, 1927; J.-P. Mahy, G. Bedi, P. Battioni and D. Mansuy, J. Chem. Soc., Perkin Trans. 2, 1988, 1517.

5 R. L.Halterman and S.-T. Jan, J. Org. Chem., 1991, 30, 5253.

6 J. A. Smegal and C. L. Hill, J. Am. Chem. Soc., 1983, 105, 2920; J. A. Smegal, B. C. Schardt and C. L. Hill, J. Am. Chem. Soc., 1983, 105, 3510 .

7 K. Noda, N. Hosoya, R. Irie, Y. Ito and T. Katsuki, Synlett, 1993, 469; H. Nishikori and T. Katsuki, Tetrahedron Lett., 1996, 37, 9245.

8 M. Johannsen and K. A. Jørgensen, J. Org. Chem., 1994, 59, 214; I. Nägeli, C. Baud, G. Bernardinelli, Y. Jacquier, M. Moran and P. Müller, Helv. Chim. Acta, 1997, 80, 1087.

Received in Cambridge, 2nd September 1997; 7/06395D 